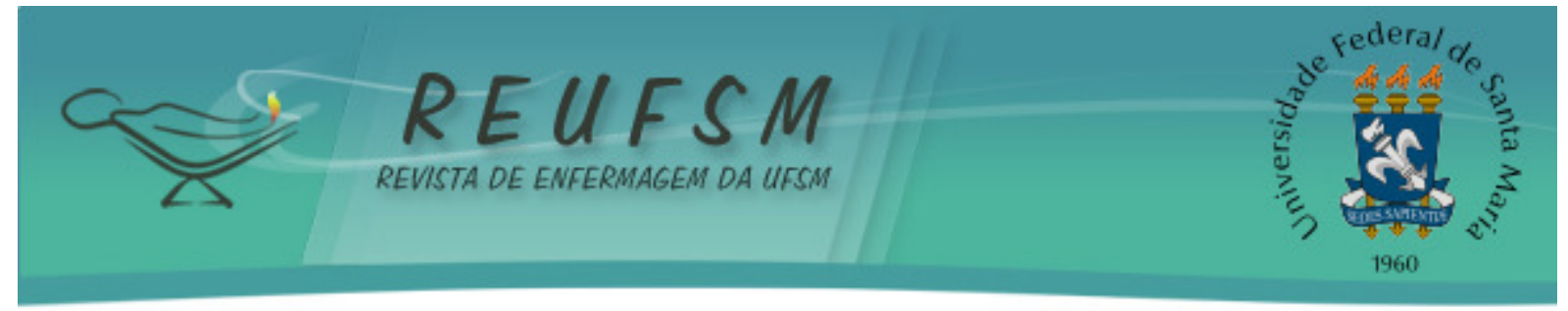

ARTIGO ORIGINAL

\title{
VIVÊNCIAS E ESTRATÉGIAS DEFENSIVAS DOS ENFERMEIROS FRENTE AO CUIDADO EM UNIDADE DE TERAPIA INTENSIVA
}

\section{NURSING EXPERIENCES AND DEFENSIVE STRATEGIES REGARDING CARE IN THE INTENSIVE CARE UNIT}

\section{VIVENCIAS Y ESTRATEGIAS DEFENSIVAS DE LOS ENFERMEROS ANTE AL CUIDADO EN UNA UNIDAD DE TERAPIA INTENSIVA}

Aline de Oliveira Moreira ${ }^{1}$ Hérica de Araújo Sousa ${ }^{2}$ Jairo Antônio Ribeiro ${ }^{3}$

RESUMO: Objetivo: identificar vivências e estratégias defensivas da equipe de enfermagem que atua na Unidade de Terapia Intensiva. Método: pesquisa qualitativa, de tipo descritivo, que utilizou a análise temática de conteúdo ao analisar os dados. Realizada com oito enfermeiros das Unidades de Terapia Intensiva Adulto e Pediátrica Mista de um hospital geral de grande porte do sul de Minas Gerais. A coleta de dados ocorreu entre julho e agosto de 2012, por meio de entrevistas semi-estruturadas. Resultados: os dados foram agrupados em três categorias: Satisfação de cuidar em Terapia Intensiva, Frustrações do cuidar na Terapia Intensiva e Lidando com as situações do dia-a-dia: mecanismos de defesa. Conclusões: os enfermeiros sentem prazer ao atuar na terapia intensiva, apesar da desvalorização se mostrar presente. 0 sentimento de quem cuida deve ser valorizado, pois isso interfere diretamente na assistência prestada e na qualidade de vida do enfermeiro intensivista.

Descritores: Cuidados intensivos; Assistência ao paciente; Relações enfermeiro-paciente; Emoções.

ABSTRACT: Objective: to identify experiences and defensive strategies in the Intensive Care Unit nursing team. Method: qualitative research, descriptive, that used the content thematic analysis when analyzing data. It was performed with eight nurses from the Adult and Mixed Pediatric Intensive Care Unit in a great general hospital in the south of Minas Gerais. The data collection occurred between July and August 2012, by means of semistructured interviews. Results: the data was gathered into three categories: Caring satisfaction in Intensive Care, Care frustration in the Intensive Care, and Coping with daily situations: defense mechanisms. Conclusions: the nurses take pleasure in working in the intensive care, in spite of under appreciation being present. The caretaker's feelings should be valued, because this interferes directly with the given assistance and life quality of the Intensive Care Nurse.

Descriptors: Intensive care; Patient Care; Nurse-patient relations; Emotions.

RESUMEN: Objetivo: identificar vivencias y estrategias defensivas del equipo de enfermeros que actúan en La Unidad de Terapia Intensiva. Método: investigación

\footnotetext{
${ }^{1}$ Enfermeira. Graduada pela Pontifícia Universidade Católica de Minas Gerais Campus Poços de Caldas. E-mail: aline_cjc@yahoo.com.br

${ }^{2}$ Enfermeira. Graduada pela Pontifícia Universidade Católica de Minas Gerais Campus Poços de Caldas. E-mail: hericahas@hotmail.com

${ }^{3}$ Enfermeiro. Mestre em Terapia Intensiva pelo Instituto Brasileiro de Terapia Intensiva. Docente do Curso de Enfermagem da Pontifícia Universidade Católica de Minas Gerais Campus Poços de Caldas. E-mail: jairojar@yahoo.com.br
} 


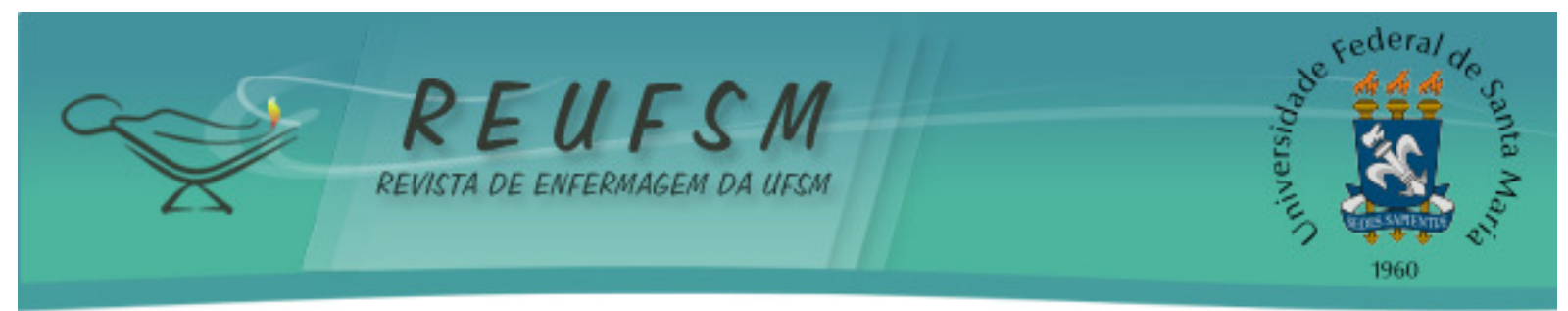

cualitativa, descriptiva, que utilizo el análisis temático de contenido al analizar los datos. Fue realizada con ocho enfermeros de las Unidades de Terapia Intensiva Adulto y Pediátrica Mixta de un hospital general de gran porte del Sur de Minas Gerais. La coleta de datos ocurrió entre julio y agosto de 2012, a través de entrevistas semiestructuradas. Resultados: los datos fueron reunidos en tres categorías: Satisfacción de cuidar en Terapia Intensiva, Frustraciones del cuidar en la Terapia Intensiva y Lidiando con situaciones del cotidiano: formas de defesa. Conclusiones: los enfermeros sienten placer en actuar en la terapia intensiva, aunque la desvalorización se muestre presente. El sentimiento de quien cuida debe ser valorado, pues eso interfiere directamente en la atención dada y en la calidad de vida del enfermero intensivista.

Descriptores: Cuidados intensivos; Atención al paciente; Relaciones enfermero-paciente; Emociones.

\section{INTRODUÇÃO}

O cuidar do ser humano é a ferramenta norteadora do exercício profissional do enfermeiro, que é um dos pilares essenciais de toda a estrutura da saúde, ${ }^{1}$ sendo o paciente o objeto direto da sua competência. ${ }^{2}$

A Unidade de Terapia Intensiva (UTI) é um setor no qual se convive com pacientes em estado grave, e que muitas vezes estão em risco iminente de morte. Assim, cuidar de pacientes nesse setor acaba, muitas vezes, desgastando a equipe de enfermagem, que passa a maior parte do tempo com o enfermo, vivenciando com ele e seu familiar, momentos de alegria e tristeza.

Esses fatores, associados à jornada de trabalho desgastante e situações de óbito, levam os enfermeiros ao estresse, resultando em frustração, impotência e cansaço. ${ }^{3}$ Dessa forma, as vivências da equipe de enfermagem interferem diretamente em sua vida social e pessoal, e pode ser fator determinante da qualidade das inter-relações, tanto no ambiente laboral como fora deste. ${ }^{4}$

Diante do exposto viu-se a necessidade de analisar as percepções dos enfermeiros diante das experiências ao cuidar de pacientes na UTI. Assim, o objetivo deste trabalho foi identificar as vivências dos enfermeiros ao cuidar e conviver com o paciente gravemente enfermo e seus familiares, e elencar estratégias defensivas que os mesmos usam para enfrentar as situações experimentadas no trabalho.

\section{MÉTODO}

Trata-se de uma pesquisa de abordagem qualitativa, tipo descritivo, realizada na Unidade de Terapia Intensiva Adulto (UTI-A) e Unidade de Terapia Intensiva Pediátrica Mista (UTIPm), de um hospital geral de grande porte localizado no sul de Minas Gerais. 0 hospital conta com 18 leitos na UTI, sendo dez deles na UTI-A e oito na UTIPm; e dez enfermeiros, sendo oito assistenciais e dois coordenadores, distribuídos igualmente nas duas unidades.

Participaram desta pesquisa oito enfermeiros, sendo cinco da UTIPm e três da UTIA. A coleta de dados ocorreu entre julho e agosto de 2012, por meio de entrevistas semiestruturadas que foram gravadas e transcritas. 0 roteiro utilizado na entrevista abordava os dados sócio-demográficos dos enfermeiros e as vivências do profissional na UTI. A análise de dados encontrou os núcleos de sentido que compõem a comunicação, na qual a presença ou frequência signifiquem alguma coisa para o objeto analítico visado. A análise temática de conteúdo desdobrou-se em três etapas: pré-análise, exploração do material, tratamento dos resultados obtidos e interpretação. ${ }^{5}$ 


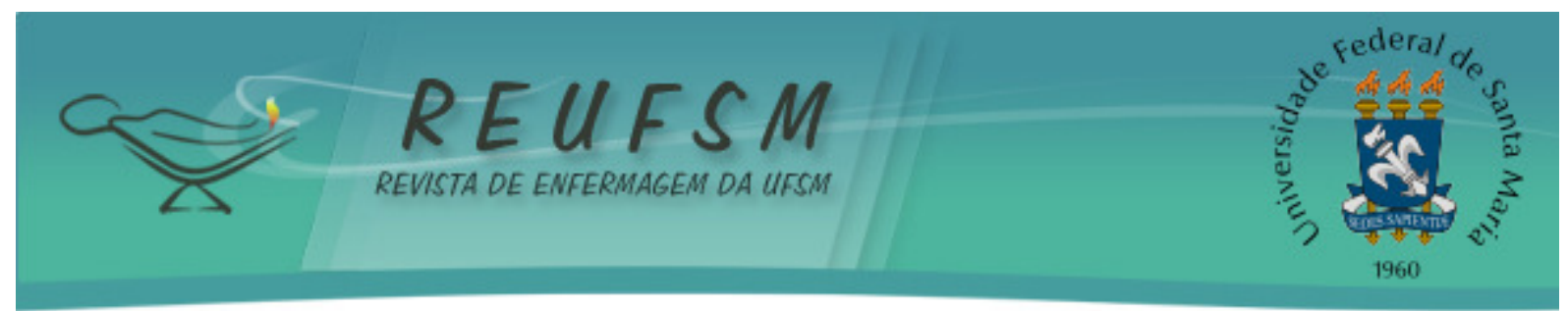

A pesquisa foi aprovada pelo Comitê de Ética em Pesquisa da Pontifícia Universidade Católica de Minas Gerais (CAAE - 0313.0.213.000-11). Foi mantido sigilo da identidade dos sujeitos, sendo identificados pela letra "E" seguida de um número.

Foram incluídos no estudo os enfermeiros que aceitaram participar da pesquisa e assinaram o Termo de Consentimento Livre e Esclarecido e excluídos os que optaram por não participar da pesquisa, os que estavam de férias e/ou licença médica.

\section{RESULTADOS E DISCUSSÃO}

Inicialmente caracterizamos a situação sócio-demográfica dos participantes do estudo, com as variáveis: idade, sexo, estado civil, tempo de profissão e titulação.

Em relação à idade, $62,5 \%$ dos entrevistados têm entre 20 e 30 anos e 37,5\% têm entre 31 e 40 anos, o que difere do estudo realizado em 2008, no qual a maioria $(62,5 \%)$ tinha entre 40 e 50 anos e apenas $25 \%$ entre 28 e 33 anos. $^{6}$

O sexo feminino prevaleceu em $87,5 \%$ dos enfermeiros, sendo apenas $12,5 \%$ do sexo masculino. Outro estudo encontrou que $75 \%$ dos entrevistados eram do sexo feminino. ${ }^{6}$

Quanto ao estado civil, $62,5 \%$ dos entrevistados são solteiros e $37,5 \%$ casados, resultado que diverge de pesquisa realizada em 2007, na qual $100 \%$ dos entrevistados eram casados. $^{7}$

Com relação ao tempo de exercício da profissão, $62,5 \%$ dos pesquisados têm entre três e quatro anos de profissão e $12,5 \%$ têm cinco anos ou mais, o que divergiu de pesquisa realizada em 2008, na qual apenas $12,5 \%$ têm cinco anos de profissão e o restante tem mais de dez anos de formação. ${ }^{6}$

Quanto à titulação, os enfermeiros são pós-graduados, sendo cinco enfermeiros com especialização em Alta complexidade, e os demais em UTI Neonatal, Terapia Intensiva e Centro de Terapia Intensiva (CTI) com Ênfase em Cardiologia, incidindo uma única vez cada um. Este resultado condiz com estudo realizado em 2008, no qual a quase totalidade dos entrevistados tinham especialização. Entretanto, apenas $12,5 \%$ possuiam pósgraduação em UTI. ${ }^{6}$

Após leitura, identificação, separação e reagrupamento, as experiências vivenciadas foram divididas nas seguintes categorias e subcategorias, em resposta às questões norteadoras:

- Satisfação de cuidar em Terapia Intensiva: A assistência ao paciente; 0 trabalho em equipe e Estendendo o cuidado aos familiares;

- Frustrações do cuidar na Terapia Intensiva: Conflitos profissionais; Vínculo com o paciente e Necessidades de melhorias ao conviver com a família;

- Lidando com as situações do dia-a-dia: mecanismos de defesa.

\section{Satisfação de cuidar em terapia intensiva}

Constatou-se que os enfermeiros sentem-se satisfeitos ao atuar na UTI, cuidando de pacientes em estado grave.

\section{A assistência ao paciente}

Ao serem questionados a respeito da escolha do setor em que trabalham, todos os profissionais alegaram que não escolheram trabalhar na UTI, porém todos demonstraram que se sentem satisfeitos. 


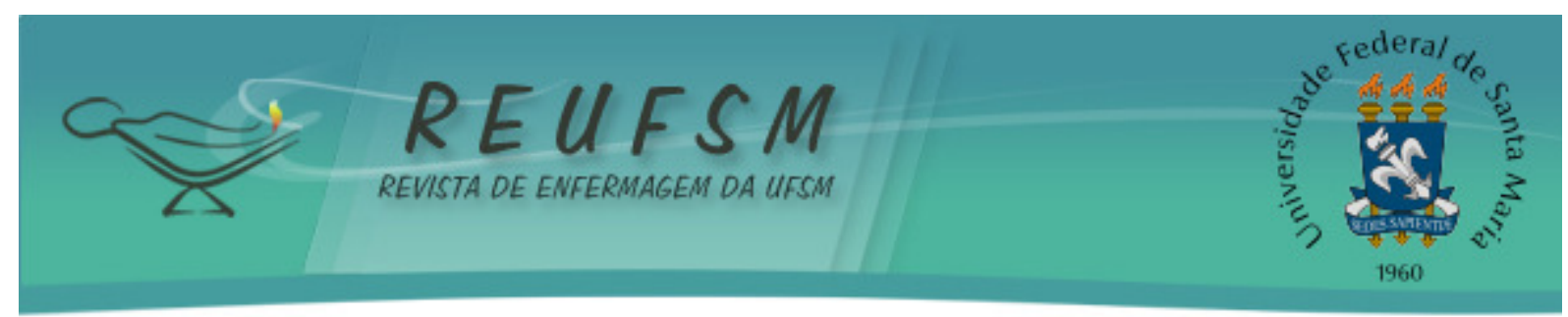

Eu me sinto realizada, eu faço o que eu gosto, gosto de cuidar de criança, cuidar de doente. (E1)

É um setor que você aprende demais [...] Cada dia você está aprendendo mais [...] (E5)

Na UTIPm há uma maior interação devido à ausência das mães, já que a enfermagem é quem primeiro promove um vínculo afetivo com as crianças. Essa relação se deve ao fato da mulher crescer preparando-se, de forma indireta, para cuidados maternos; e assim, ao escolher uma profissão, acaba procurando uma que vá de encontro com esse aprendizado. $^{3}$

Já na UTI-A a afinidade se destacou pelo cuidado ao paciente crítico e constante aprendizado. Os profissionais percebem a assistência ao paciente como ponto positivo, já que se tem um maior controle de ações, o que lhes dá certeza de um resultado satisfatório. Ao cuidar do paciente, o enfermeiro tem a oportunidade e a liberdade para regular suas tarefas, favorecendo uma assistência mais próxima e minuciosa aos pacientes críticos e dependentes. ${ }^{4}$

0 aprendizado e o gosto pela complexidade são atribuídos à possibilidade de crescer, adquirindo conhecimentos técnico-científicos e criando um cuidar diferente. ${ }^{8}$

A satisfação quando há a recuperação de um paciente também se destacou como gerador de prazer:

\section{[...] Quando dá tudo certo é muito feliz você encontrar com o paciente na ala, na rua, você vê que saiu [...] (E4)}

Os profissionais denotam imensa satisfação com a recuperação do paciente que esteve sob seus cuidados e um reencontro posterior deixa transparecer que seus cuidados foram efetivos.

O prazer que o enfermeiro vivencia é em parte resultante da recuperação do paciente, de forma especial quando outros já não acreditavam na possibilidade de cura. ${ }^{4}$

\section{0 trabalho em equipe}

O trabalho em equipe é tido como satisfatório:

[...] Aqui na Neo, assim, o setor é bem agradável, todo mundo trabalha em conjunto, com um só objetivo. (E5)

Os sujeitos entendem a importância de se trabalhar em equipe, ajudando uns aos outros e focando em um só objetivo: a restauração da saúde do doente. Não houve demonstração de divergências ou discussões entre a equipe de enfermagem, divergindo de estudo no qual o enfermeiro convive com a falta de responsabilidade dos funcionários, e do médico. A valorização e promoção da interação grupal podem resultar na criação de vínculos afetivos, que desperta sentimentos de prazer e cria meios de exposição de ideias. ${ }^{6}$

\section{Estendendo o cuidado aos familiares}

O cuidado não fica restrito ao paciente, há a preocupação em dar atenção também aos familiares: 


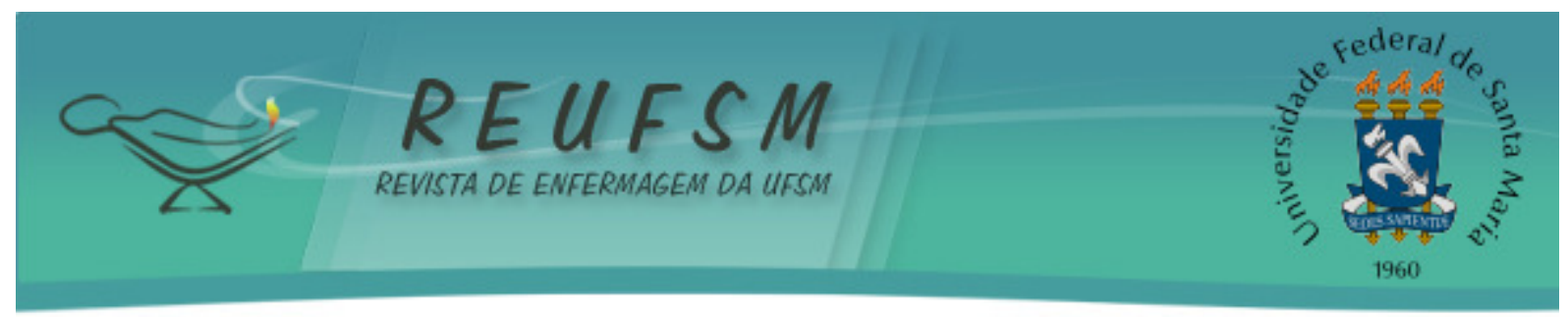

No começo é muito complicado, é uma conquista de confiança, depois a gente já vai conseguindo, até ser um pouco amigo, um pouco psicólogo, tá ali junto dando força... não tem como não ter uma aproximação, porque as crianças passam muito tempo aqui dentro. (E3)

A gente tem um horário de visitas, é o momento que a gente tem pra conversar com a família, conhecer a história e dar um apoio porque não é fácil. (E4)

Os enfermeiros, ao cuidarem de neonatos, aproximam-se mais das mães dos pacientes devido ao estado emocional no qual elas se encontram, tentando ajudá-las, criando um vínculo de confiança e respeitando o espaço da mãe com seu filho.

$\mathrm{Na}$ UTI-A notou-se que o contato com os familiares é restrito ao horário de visitas, no qual além de tentar oferecer um apoio aos familiares, também é um momento propício para reconhecer a história do paciente e sua família, suas necessidades e dificuldades. A UTI é um ambiente estranho e estigmatizado pelos familiares, surgindo a necessidade do enfermeiro ter habilidade para comunicar-se com os familiares, a fim de diminuir inseguranças e medo, além de humanizar a assistência ao paciente e a todos os envolvidos. ${ }^{4}$

\section{Frustrações do cuidar na terapia intensiva}

Constatou-se que os profissionais se sentem frustrados diante de algumas situações vivenciadas. Destacaram-se os conflitos profissionais, o vínculo com o paciente e a necessidade de melhorias na convivência com a família.

\section{Conflitos profissionais}

Os conflitos profissionais se destacaram devido à desvalorização profissional, sentimento de impotência e conflitos com a equipe médica.

Todo mundo gosta de receber elogios, querer que o seu trabalho seja reconhecido, e acho que algumas vezes isso não acontece. (E5)

É de extrema importância que o trabalhador seja reconhecido e valorizado pelos pacientes, familiares, equipe de trabalho, instituição e sociedade ao desempenhar suas funções. ${ }^{4}$ A desvalorização do familiar em relação ao enfermeiro pode estar associada à herança do modelo clínico de atendimento, no qual o médico é visto como aquele que tem o poder da cura. ${ }^{6} \mathrm{O}$ reconhecimento e a valorização individual e da equipe devem ser desenvolvidas pelas lideranças, já que tem um impacto muito positivo no trabalho. ${ }^{1}$

A impotência se faz presente em alguns momentos:

[...] poderia ter sido evitado na rede, no sistema, antes de chegar a complicar. (E1)

Algumas vezes eu me senti um pouco impotente, porque a gente tem dó, quer ajudar, quer fazer alguma coisa, mas sabe que já não tem mais o recurso, o recurso que tem já ta sendo feito [...] Têm alguns casos, você sabe que pode ser feito algo mais [...] (E4) 


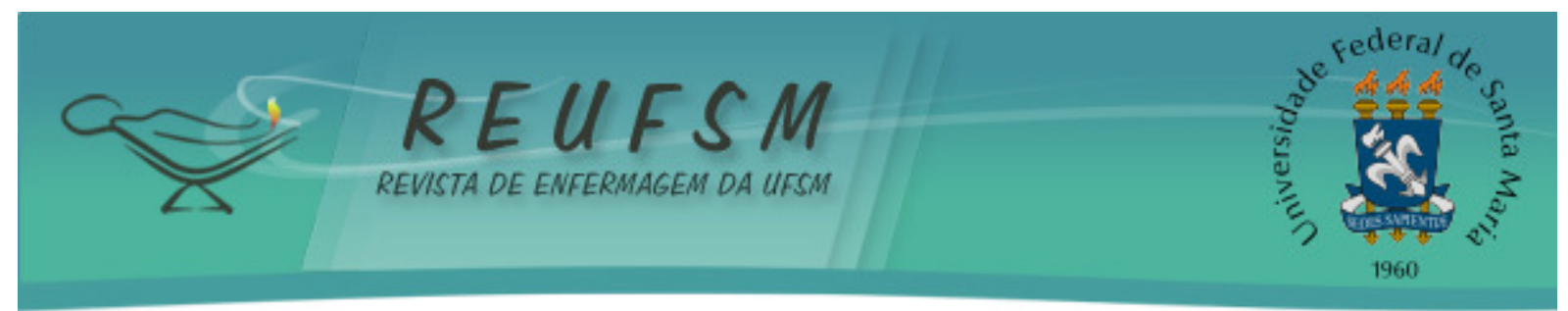

Apesar de todo o recurso tecnológico da UTI, em muitos casos esse aparato não é suficiente, sendo preciso aceitar que não há mais nada a ser feito e que as coisas não vão evoluir bem.

Enfatiza-se aqui a frustração por algo que poderia ter sido evitado na rede antes de chegar à atenção terciária. Essa deficiência da atenção primaria à saúde pode ser atribuída, entre outros fatores, ao fato da sociedade ainda ter em mente um modelo curativista, buscando o serviço de saúde apenas quando se vê doente, deixado de prevenir doenças e complicações. Em estudo realizado em 2012 os entrevistados referem ter consciência da importância das atividades de promoção de saúde e prevenção de doenças, mas ainda não a colocam como essenciais para a ida até a unidade. A busca da unidade deve-se à presença de doença, necessidade de um procedimento curativo ou busca de medicamentos. ${ }^{9}$

As divergências entre enfermeiros e médicos também foram observadas quando cada um fica restrito às suas funções, prejudicando a assistência ao paciente e convívio com os familiares.

Os médicos não gostam que a gente converse com a família... Falam que às vezes a gente pode falar alguma informação incorreta. A gente não concorda com isso. (E7)

A desvalorização pode interferir quando há um confronto indireto com a equipe médica, gerando uma separação errônea de funções e dificultando o trabalho multidisciplinar. Assim, médicos se reúnem de um lado e equipe de enfermagem de outro, não havendo um diálogo harmonioso.

0 apoio e a assistência da equipe de saúde aos familiares levam-nos a se sentirem mais seguros e confiantes na recuperação do ente, a conhecerem melhor a UTI, a perceber este espaço como o mais preparado para receber o paciente, e proporcionar melhores condições de sobrevivência. ${ }^{10}$

\section{Vínculo com o paciente}

Em certas situações é impossível não envolver-se com o paciente. Por diversas vezes esse vínculo leva o profissional ao sofrimento e muitos não conseguem desvincular vivências profissionais e pessoais, levando o problema do paciente para sua casa, tomando para si as dificuldades da família e condição do paciente.

Essa história que você separa o profissional do pessoal não existe. Você acaba realmente levando um pouquinho do paciente com você, uma preocupação. Você não consegue desvincular. (E2)

A gente vê o sofrimento de um ser tão pequenininho, é muito sofrido. (E3)

É quase impossível impedir que haja afeto com os familiares e os pacientes. Há o despertar de sentimentos, mesmo quando não são expressos. ${ }^{6} 0$ sofrimento ao envolver-se com o paciente é agravado pelo despreparo na formação profissional, pela sobrecarga de trabalho e insatisfação, dificultando o relacionamento com o paciente. ${ }^{1}$ Esse sentimento, na UTIPm, pode ser atribuído à dificuldade em lidar com as perdas de pessoas jovens. ${ }^{11}$

A sobrecarga de trabalho é outro ponto relevante, comprometendo a assistência do enfermeiro ao paciente: 


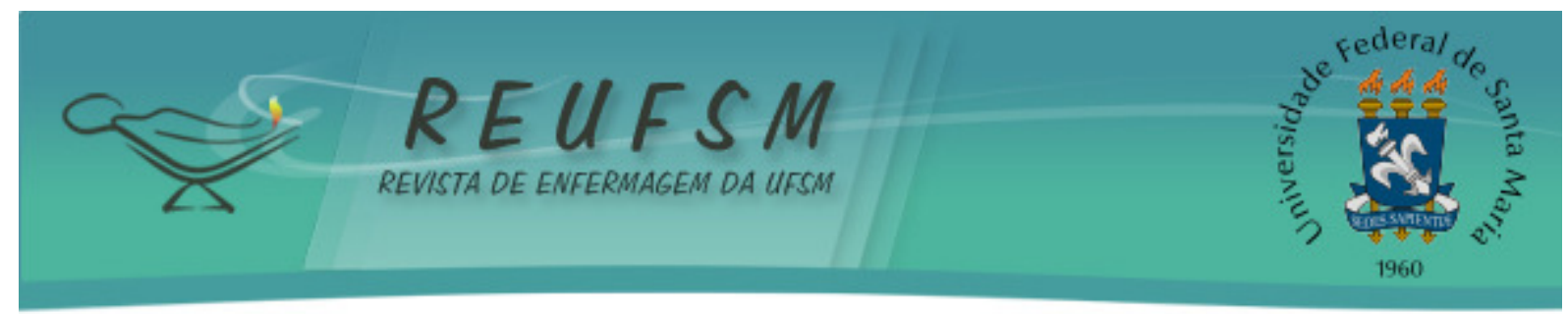

Com o paciente, tem uma certa interação, mas durante o dia [...] $A$ gente não tem muito tempo, sinceramente, devido às nossas funções. (E8)

A qualidade da assistência está diretamente relacionada às atividades do enfermeiro, nas suas ações de planejamento da estrutura, processos desenvolvidos e participação na decisão sobre a alta do paciente. ${ }^{12}$ Os profissionais se sentem sobrecarregados, desejando dar mais atenção ao paciente, focar e ajudar mais, porém o excesso de trabalho e as questões burocráticas prejudicam a assistência.

A sobrecarga de atividades gera insatisfação e aumento de desgaste físico e mental, inviabilizando e prejudicando a assistência. ${ }^{8}$

Percebe-se que há uma tentativa de humanizar a assistência:

Os pacientes que estão acordados a gente tenta conversar porque eles não conseguem dormir [...] Mas tem paciente confuso, desacordado, é mais difícil, tem as vezes que conter no leito, se machucam. E os que estão sedados a gente conversa, fala o que ta fazendo, onde tocar... Num tem muita coisa que se possa fazer. (E4)

A humanização é um processo de cuidar do paciente como um todo, em seu contexto familiar e social, incorporando e respeitando os seus valores, esperanças, aspectos culturais e preocupações. ${ }^{1}$ Percebe-se que a humanização não está totalmente inserida na UTI. Há a necessidade de se retomar valores abandonados, olhar de modo diferente e integrado, onde razão e sensibilidade possam caminhar juntas. ${ }^{2}$ Contudo, é importante limitar o vínculo, tomando o cuidado de não projetar para si o sofrimento do outro. ${ }^{11}$

\section{Necessidades de melhorias ao conviver com a família} melhorar:

Alguns entrevistados colocam que a relação com a família ainda tem muito a

A equipe de setor fechado não é acostumada a trabalhar com a família [...] Tem que trabalhar com muita cautela com a equipe $e$ com a família, para que a equipe aceite essa mãe. (E1)

Para a maioria das pessoas internadas e para seus familiares, a UTI gera medo e ansiedade, sendo um momento estressante na vida de todos.

Os profissionais se sentem despreparados para conviver com as mães dos neonatos internados. $O$ fato dessas crianças serem esperadas e amadas faz com que muitas mães se revoltem e não aceitem a situação. Assim, há a necessidade de se dar uma atenção maior a essas pessoas e fazer com que essas mães entendam o que está acontecendo, atendendo aos seus anseios, mesmo que isto vá contra as normas e rotinas do setor.

A discussão a respeito da permanência dos familiares na UTI é controversa, mas deve ser analisada a possibilidade de se ajustar o horário de permanência do familiar no setor e o espaço físico para atender e dar a atenção necessária aos mesmos. ${ }^{1}$

É difícil de interagir com a família [...] Nem sempre tem estrutura pra isso, tanto pra receber essa mãe e espaço físico também, a gente não tem adequado. ( $\mathrm{E} 1)$ 


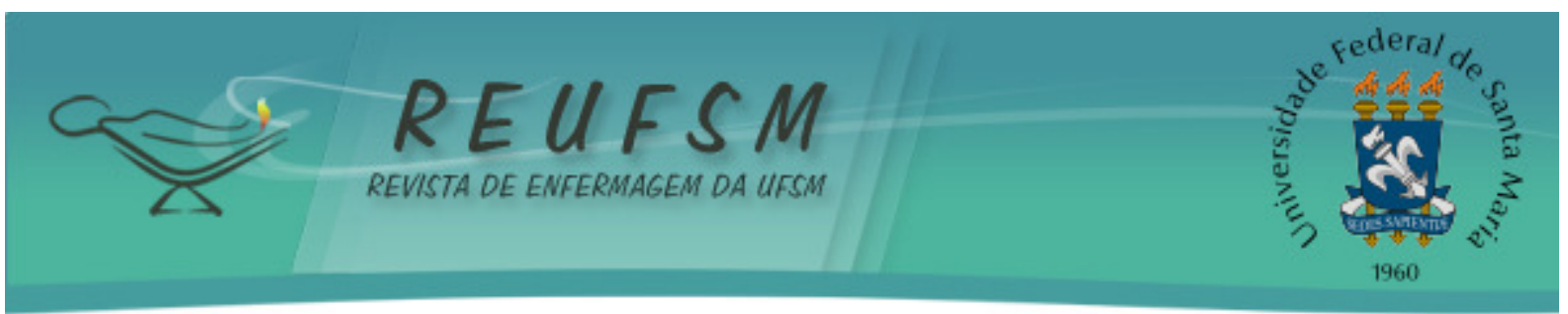

O local inadequado é tido como um fator negativo nas relações interpessoais, dificultando o encontro e diálogo entre familiares e enfermeiros. ${ }^{13}$

Outro ponto que chama a atenção é quanto ao tecnicismo, onde os funcionários relatam que muitas vezes acabam se esquecendo do sofrimento do familiar:

[...] tem que tá muito atento ao nosso comportamento, principalmente no horário de visitas, eles prestam atenção em tudo que você faz e tudo que você fala, tem que se policiar, a gente fica muito tecnicista, esquece muito da parte humana, de se colocar no lugar do outro. (E5)

O tecnicismo apresenta-se como forma de defesa, distanciando o enfermeiro do paciente, prejudicando e limitando o cuidado. Há a necessidade de mudança de valores, resgatando o sentido de ser humano, onde o paciente seja visto e considerado como indivíduo dotado de modo de ser, sentir e se expressar. ${ }^{2}$

\section{Lidando com as situações do dia-a-dia: mecanismos de defesa}

Diante das conflituosas experiências nas quais os enfermeiros estão envolvidos, torna-se necessária a criação de estratégias que os ajudem a aceitar o sofrimento. ${ }^{6}$

Ao serem questionados se recebem apoio terapêutico da instituição, seis dos oito entrevistados referem ter um psicólogo à disposição. Destes, três referem ter procurado ajuda profissional, sendo que um alegou não ter gostado do serviço. Os outros dois referem desconhecer esse apoio:

Eu comecei a fazer terapia com ela, eu achei que foi muito bom, porque a gente consegue um pouco tirar esses monstros. Ela é muito competente, muito acessível. (E7)

$\mathrm{Na}$ manutenção da vida, pode haver um desgaste profissional, o que leva à necessidade de suporte psicológico para lidar com as situações que se tornam rotineiras. ${ }^{3}$ Cabe às instituições promover capacitações e oferecer acompanhamento psicológico, diminuindo o absenteísmo, os riscos de acidente e doenças ocupacionais. ${ }^{2}$

Entre os mecanismos de defesa, o afastar-se da situação se destacou:

Depois que o bebê sai daqui, parece que eu me bloqueio, que eu não lembro mais [...] Se a gente se envolve muito, a gente não consegue trabalhar. (E3)

Quando eu me sinto mal com alguma coisa, eu prefiro, naquele momento, não lidar com a situação. (E1)

O afastamento é um dos meios utilizados para se defender ou diminuir o sofrimento. Quando se percebe que as chances dos pacientes são mínimas e há receio da morte surgem sentimentos de afastamento como forma de proteção. ${ }^{6}$

O enfermeiro sabe que não pode levar para casa o que se passa na UTI, mas ainda são fortes os laços estabelecidos. O afastamento ocorre, entre outros motivos, por não estarem preparados para enfrentar a morte, já que o ensino na faculdade é mais voltado para salvar vidas, curar, prevenir e promover a saúde, e não para lidar com a morte. ${ }^{11}$

Há relatos também de ajuda entre colegas da equipe: 


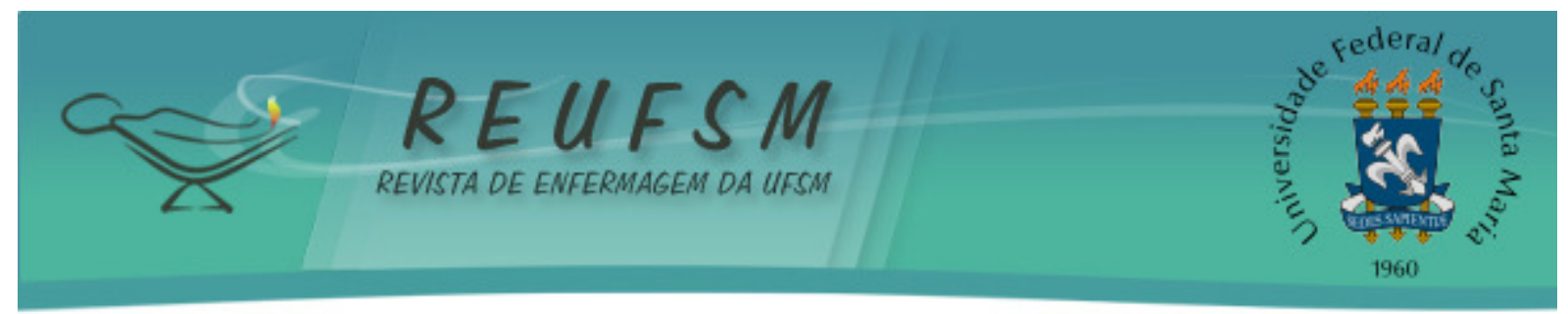

A gente mesmo conversa entre a gente. (E6)

A gente entra, tenta descontrair o ambiente, tenta fazer brincadeiras entre a gente, porque senão a gente não dá conta. (E7)

O desabafo, as conversas e a tentativa de descontrair o ambiente estão presentes. Percebe-se aqui a maior facilidade que as mulheres têm de se expressar, os enfermeiros são mais fechados, restringindo seus desabafos com colegas homens. Entretanto, notou-se que há um bom entrosamento da equipe e consequente troca de experiências.

O trabalho em equipe, amizade e companheirismo são importantes, pois levam os profissionais a compartilhar experiências, vivências e conhecimentos e proporcionam a confiança entre si. ${ }^{11}$

Também se encontrou a espiritualidade como mecanismo de defesa:

Eu tenho uma fé, eu acredito em Deus, todo dia que eu venho trabalhar eu peço a Deus pra ajudar, dar sabedoria e a gente tem que confiar na gente mesmo, na equipe, ser ponderada, saber ouvir e falar no momento certo. (E5)

A espiritualidade nasce como essência do ser, uma ligação com Deus ou seres superiores que precisa ser valorizada tanto quanto as forças existenciais, fenomenológicas e espirituais presentes no cuidado humano. ${ }^{2}$

\section{CONCLUSÃO}

Com esse estudo percebeu-se que os enfermeiros gostam de atuar na UTI e sentem-se satisfeitos ao cuidar do paciente crítico, principalmente quando veem a sua reabilitação.

O sentimento de desvalorização e impotência se fez presente de modo acentuado nas falas dos sujeitos. O vínculo que o enfermeiro cria com o paciente também foi apontado como negativo para o profissional, a medida que se envolve de forma a tomar para si as dores dos pacientes e familiares, o que afeta sua vida.

Como métodos de enfrentamento das situações difíceis, a maioria dos profissionais se afasta dos pacientes, a fim de não se envolverem.

O estudo apontou para a necessidade de uma formação humanista, bem como divulgação mais abrangente de programas e terapias de apoio psicológico que a instituição empregadora oferece.

A partir daí, julga-se necessária e indispensável a continuidade de pesquisas nessa área, a fim de identificar as necessidades, desafios e dificuldades dos profissionais, visto que não se pode deixar de lado os sentimentos de quem cuida, pois isso interfere diretamente na assistência prestada e na qualidade de vida do enfermeiro intensivista.

\section{REFERÊNCIAS}

1. Knobel E. Terapia intensiva: enfermagem. São Paulo: Atheneu; 2006. 636 p.

2. Valli A. Sentimentos dos enfermeiros na Unidade de Terapia Intensiva frente ao paciente em estágio terminal [monografia]. Novo Hamburgo (RS): Centro Universitário Feevale; 2007 [acesso em 2012 ago 2]. 43 p. Disponível em: http://ged.feevale.br/bibvirtual/Monografia/MonografiaAlineLeao.pdf. 


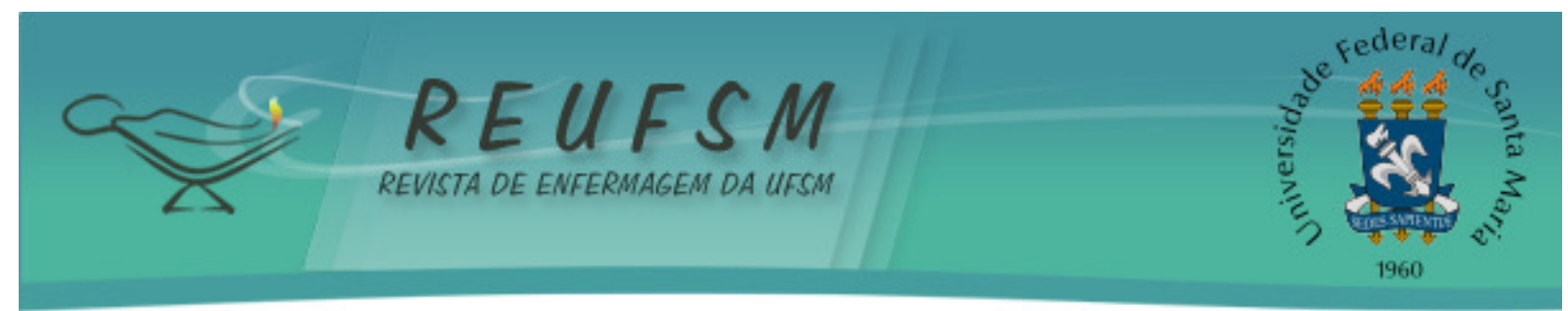

3. Ávila SP. Sentimentos presentes na equipe de enfermagem na Unidade de Terapia Intensiva Neonatal diante dos neonatos internados [monografia]. Tubarão [SC]: Universidade do Sul de Santa Catarina; 2010 [acesso em 2012 ago 2]. 64 p. Disponível em: http://portal2.unisul.br/content/navitacontent_/userFiles/File/cursos/cursos_graduacao/ Psicologia-tb/tcc2010-a/Sheila_Avila.pdf.

4. Martins JT, Robazzi MLCC, Garanhani ML. Sentimentos de prazer entre enfermeiros de Unidades de Terapia Intensiva. Cienc Enferm [Internet]. 2009 [acesso em 2012 out 28];15(3):4553. Disponível em: http://www.scielo.cl/scielo.php?script=sci_arttext\&pid=S071795532009000300006\&lng=es. doi: 10.4067/S0717-95532009000300006.

5. Minayo M. O desafio do conhecimento: pesquisa qualitativa em saúde. São Paulo: Hucitec; 2010.

6. Martins JT. Prazer e sofrimento no trabalho do enfermeiro em Unidades de Terapia Intensiva: estratégias defensivas [tese]. Ribeirão Preto: Universidade de São Paulo, Escola de Enfermagem de Ribeirão Preto; 2008 [acesso em 2012 ago 2]. 201 p. Disponível em: http: / /www.teses.usp.br/teses/disponiveis/83/83131/tde-06102008-151026.

7. Albuquerque NMGA. Vivência do enfermeiro no cuidado humano na Unidade de Terapia Intensiva Adulto [dissertação]. Natal: Universidade Federal do Rio Grande do Norte; 2007 [acesso em 2012 ago 2 ]. $136 \quad$ p. $\quad$ Disponível http://bdtd.bczm.ufrn.br/tedesimplificado/tde_arquivos/5/TDE-2007-12-07T045639Z973/Publico/NicelhaMGA.pdf.

8. Salomé GM, Espósito VHC, Silva GTR. O ser profissional de enfermagem em Unidade de Terapia Intensiva. Acta Paul Enferm. 2008;21(2):294-9.

9. Franco ECD. A estratégia de saúde da família na perspectiva do usuário. Rev Enferm UFSM [Internet]. 2012 jan/abr [acesso em 2012 dez 4];2(1):49-58. Disponível em: http://cascavel.ufsm.br/revistas/ojs-2.2.2/index.php/reufsm/article/view/4002/3142.

10. Silva LWS, Santos FF, Souza DM. Sentimentos da família diante do enfrentamento do viver-morrer do membro familiar na UTI. Rev Enferm UFSM [Internet]. $2011 \mathrm{set} / \mathrm{dez}$ [acesso em 2012 dez 4];1(3):420-30. Disponível em: http://cascavel.ufsm.br/revistas/ojs2.2.2/index.php/reufsm/article/view/3604/2408.

11. Martins JT, Robazzi MLCC. $O$ trabalho do enfermeiro em unidade de terapia intensiva: sentimentos de sofrimento. Rev Latinoam Enferm. 2009 fev;17(1):52-8.

12. Favarin SS, Camponogara S. Perfil dos pacientes internados na Unidade de Terapia Intensiva Adulto de um Hospital Universitário. Rev Enferm UFSM [Internet]. 2012 mai/ago [acesso em 2012 dez 4];2(2):320-9. Disponível em: http://cascavel.ufsm.br/revistas/ojs2.2.2/index.php/reufsm/article/view/5178/3913.

13. Ruedell LM, Beck CLC, Silva RM, Lisboa RL, Prochnow A, Prestes FC. Relações interpessoais entre profissionais de enfermagem e familiares em Unidade de Tratamento Intensivo: estudo bibliográfico. Cogitare Enferm. 2010 jan/mar;15(1):147-52.

Data de recebimento: $28 / 11 / 2012$

Data de aceite: 13/05/2013

Contato com autor responsável: Aline de Oliveira Moreira

Endereço postal: Rua Bolivar Prado, 260, Centro - Cachoeira de Minas/MG CEP 37545-000

E-mail: aline_cjc@yahoo.com.br 